\title{
a systematic review and meta-analysis
}

\author{
Ye Feng ${ }^{1}$, Zhe Zhang $^{1}$ and Zhou-zhou Dong ${ }^{2}$
}

BACKGROUND: Evidence suggests that $15-30 \%$ of individuals with obstructive sleep apnoea (OSA) have type 2 diabetes mellitus (T2DM), and that OSA is an independent risk factor for T2DM. There is considerable interest in ascertaining whether OSA treatment improves glycaemic control and insulin sensitivity in patients with OSA and T2DM.

AIMS: To assess the effects of continuous positive airway pressure (CPAP) therapy on glycosylated haemoglobin (HbA1c) level, insulin sensitivity and body mass index (BMI) in patients with OSA and T2DM.

METHODS: MEDLINE, EMBASE and the Cochrane Library were searched to identify prospective studies involving patients with OSA and T2DM who had received CPAP, and data on primary outcome (change in $\mathrm{HbA1c}$ ) and/or secondary outcomes (changes in insulin sensitivity and BMI) were reported. All relevant studies published before 31 January 2014 were included.

RESULTS: Six studies were included in the systematic review and meta-analysis. The numbers of patients ranged from 9 to 44 (total $=128$ ), and mean age ranged from 50.7 to 66.1 years. For the change in $\mathrm{HbA} 1 \mathrm{c}$ (six studies, 128 patients), the combined standardised paired difference revealed no significant effect of CPAP $(-0.071,95 \%$ confidence interval $(\mathrm{Cl})=-0.245,0.103$; $P=0.421)$. Similarly, there was no significant effect of CPAP on the change in $\mathrm{BMI}(-0.102,95 \% \mathrm{Cl}=-0.296,0.092 ; P=0.302 ;$ five studies, 103 patients). In contrast, there was a significant effect of CPAP on the change (improvement) in insulin sensitivity (0.330, $95 \% \mathrm{Cl}=0.001,0.658 ; P=0.049$; three studies, 39 patients).

CONCLUSION: The limited available evidence from randomised controlled trials and prospective observational studies suggests that CPAP does not decrease HbA1c level or BMI in patients with OSA and T2DM but may improve insulin sensitivity.

npj Primary Care Respiratory Medicine (2015) 25, 15005; doi:10.1038/npjpcrm.2015.5; published online 26 February 2015

\section{INTRODUCTION}

Obstructive sleep apnoea (OSA) is a relatively prevalent condition, particularly among men, and has a number of negative health consequences. Epidemiologic studies have shown that up to $24 \%$ men experience some form of OSA, ${ }^{1}$ with those who are overweight or obese being particularly susceptible. ${ }^{2}$ In addition to excessive daytime sleepiness, which is the hallmark symptom of OSA, individuals with OSA have an increased risk of developing a number of comorbidities including cardiovascular disease, hypertension, metabolic disease and diabetes. ${ }^{3,4}$ With regard to diabetes, evidence from a number of studies suggests that $15-30 \%$ of individuals with OSA have type 2 diabetes mellitus (T2DM) and that OSA is an independent risk factor for T2DM. ${ }^{5}$

A variety of potential mechanisms, including OSA-related hypoxia (leading to activation of the sympathetic nervous system and hyperglycaemia), altered anterior pituitary and adrenal activation affecting glycaemic control, direct effects of hypoxia on glucose metabolism and insulin sensitivity and increased release of cytokines contributing to insulin resistance have been proposed to explain the link between OSA and T2DM. ${ }^{6}$ Despite this, a causal link between OSA and T2DM has not been proven. ${ }^{5}$ Nevertheless, the aforementioned association between OSA and T2DM has generated considerable interest in ascertaining whether treatment of OSA also improves glycaemic control and insulin sensitivity in patients with OSA and T2DM.

Continuous positive airway pressure (CPAP) therapy is the gold standard treatment for OSA. Although CPAP can be a very effective treatment for OSA, the effects of such treatment on comorbidities such as T2DM remain less clear cut, with evidence from some studies suggesting that CPAP is effective in improving insulin resistance and evidence from others suggesting that CPAP has no effect. ${ }^{5-7}$ In an attempt to gain further insight into the question whether CPAP is an effective treatment for T2DM in patients with OSA, Iftikhar and Blankfield ${ }^{8}$ carried out a systematic review and meta-analysis (published in 2012) examining the effects of short-term CPAP on glycosylated haemoglobin (HbA1c) level in patients with OSA and T2DM. Overall, they found no evidence that CPAP decreased the $\mathrm{HbA1c}$ level in these patients. However, the analysis included only four prospective studies (in addition to one retrospective study) and did not examine other indicators of T2DM, such as insulin sensitivity. A more recent systematic review by Gallegos et al. ${ }^{9}$ reported improvement in $\mathrm{HbA} 1 \mathrm{c}$ level and/or increased insulin activity, but only after long-term CPAP use ( $\geqslant 3$ months).

The aim of the present systematic review and meta-analysis was to perform an up-to-date examination of the prospective study

\footnotetext{
'Department of Endocrinology, The First Affiliated Hospital, Zhejiang University School of Medicine, Hangzhou, Zhejiang, China and ${ }^{2}$ Department of Intensive Care Unit, Ningbo Medical Treatment Center Lihuili Hospital, Ningbo, China.

Correspondence: Y Feng (yunyi_0513@163.com)

Received 19 June 2014; revised 21 December 2014; accepted 28 December 2014
} 
literature to determine the effects of CPAP treatment on indicators of T2DM, including glycaemic control (HbA1c level) and insulin sensitivity, in patients with OSA and T2DM. We also examined the effects of CPAP treatment on body mass index (BMI).

\section{MATERIALS AND METHODS}

\section{Selection criteria}

Studies were considered for inclusion if they were randomised controlled trials or prospective observational studies and included patients with T2DM and stable disease who received CPAP for the treatment of OSA.

Studies were excluded if they involved patients who did not have diagnosed T2DM or had not received treatment for T2DM, were retrospective in design, did not report the pretreatment and posttreatment effects of CPAP on HbA1c, insulin sensitivity (assessed by hyperinsulinaemic-euglycaemic clamp) or BMI, or were published in a language other than English.

\section{Search strategy}

MEDLINE, EMBASE and the Cochrane Library were searched from inception to 31 January 2014 using combinations of the following key terms: diabetes mellitus, obstructive sleep apnoea, continuous positive airway pressure, glycaemic control, insulin sensitivity, BMI. Reference lists of relevant studies were hand-searched in an attempt to identify other potentially relevant studies.

\section{Study selection and data extraction}

Studies were identified by two independent reviewers using the aforementioned search strategy. Where there was uncertainty regarding eligibility, a third reviewer was consulted. The following information/data were extracted from studies that met the eligibility criteria: name of the first author; year of publication; study design; number of participants; participants' age and sex; CPAP regimen; and HbA1c, insulin sensitivity, weight and BMI data before and after CPAP. In the event that numeric data for outcome measurements were lacking, we requested mean and s.d. values for before and after CPAP from the authors. To combine the outcomes of two-arm comparative studies (for example, randomised controlled trials) with those of one-arm observational studies, we extracted data for the treatment group only from comparative studies.

\section{Outcome measures}

The primary outcome was change in HbA1c level after CPAP. Secondary outcomes included changes in insulin sensitivity and BMI after CPAP. There are several measures for insulin sensitivity: for example, homeostatic model assessment (HOMA), quantitative insulin sensitivity check index and hyperinsulinaemic-euglycaemic clamp. We included only those studies that measured insulin sensitivity using the hyperinsulinaemic-euglycaemic clamp, which is a very sensitive measurement for this outcome.

\section{Quality assessment}

The methodologic quality of each study was assessed with the use of the risk-of-bias assessment tool outlined in the Cochrane Handbook for Systematic Reviews of Interventions. ${ }^{10}$ Two reviewers subjectively reviewed all the studies and assigned a value of 'low risk,' 'high risk' or 'unclear' for the following: (a) random sequence generation; (b) allocation concealment; (c) blinding (patients, personnel and assessor); (d) adequate assessment of each outcome; (e) avoidance of selective outcome reporting; and (f) inclusion of an intent-to-treat analysis.

\section{Statistical analysis}

Combined summary statistics of the standardised paired difference in mean for the individual studies are shown. The standardised mean difference is used as a summary statistic in meta-analysis when the studies all assess the same outcome but measure it in a variety of ways. ${ }^{11}$ The standardised mean difference expresses the size of the intervention effect in each study relative to the variability observed in that study as follows: standardised mean difference $=$ difference in mean outcome between groups/s.d. of outcome among participants. ${ }^{11}$

A $X^{2}$-based test of homogeneity was performed, and the inconsistency index $\left(l^{2}\right)$ statistic was determined. Random-effects models of analysis were used if heterogeneity was detected $\left(I^{2}>50 \%\right)$. Otherwise, fixed-effects models were considered. Combined standardised paired differences in means were calculated, and a two-sided $P$ value $<0.05$ was considered to indicate statistical significance. An unplanned subgroup analysis of $\mathrm{HbA} 1 \mathrm{C}$ level according to CPAP usage duration was performed. Sensitivity analysis was carried out for the outcomes using the leave-one-out approach. Publication bias was assessed by constructing funnel plots for primary outcome. Absence of publication bias is indicated by data points forming a symmetric, funnel-shaped distribution. All analyses were performed with comprehensive meta-analysis statistical software, version 2.0 (Biostat, Englewood, NJ, USA).

\section{RESULTS}

Study selection

After the removal of duplicates, a total of 2,165 records were screened for eligibility (Figure 1). Of these, 2,154 were excluded,

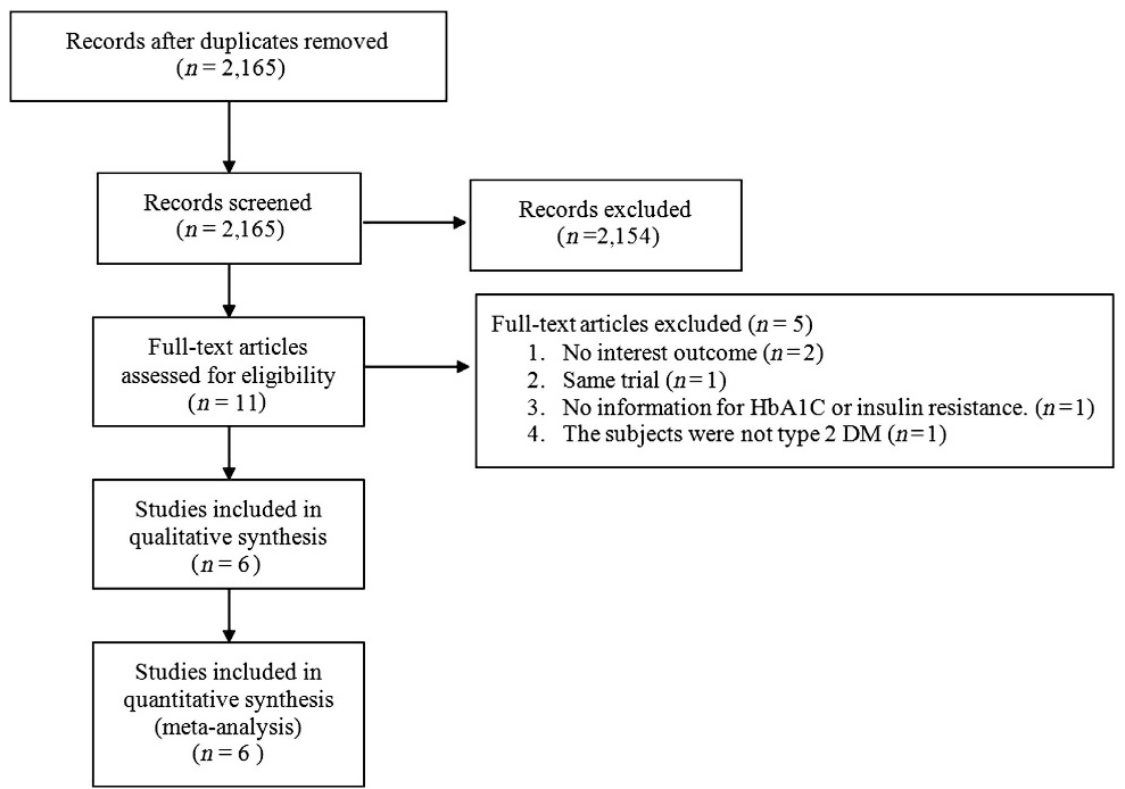

Figure 1. Flow chart for study selection. DM, diabetes mellitus; HbA1c, glycosylated haemoglobin. 
Table 1. Characteristics of the studies included in the meta-analysis

\begin{tabular}{llccccccc}
\hline $\begin{array}{l}\text { First author } \\
\text { (year) }\end{array}$ & Study design & $\begin{array}{c}\text { Patients, } \\
\mathrm{n}\end{array}$ & Age, years & $\begin{array}{c}\text { Sex, } \\
\% \text { male }\end{array}$ & $\begin{array}{c}\text { Baseline BMI, } \\
\mathrm{kg} / \mathrm{m}^{2}\end{array}$ & $\begin{array}{c}\text { Duration of diabetes, } \\
\text { years }\end{array}$ & $\begin{array}{c}\text { Treatment } \\
\text { CPAP, }\end{array}$ \\
\hline Myhill $^{12}$ & RCT & 44 & $66.1 \pm 8.8$ & 61.4 & $33.6 \pm 5.5$ & $10.1(3.8,15.3)^{\mathrm{a}}$ & CPAP for 3 months \\
Dawson $^{13}$ & Observational & 20 & $59.8 \pm 10.2$ & 60 & $39.6 \pm 8.0$ & $9.8 \pm 7.7$ & CPAP for 3 months \\
West $^{14}$ & RCT & 20 & $57.8 \pm 10.4$ & 100 & $36.6 \pm 4.9$ & 7.3 & CPAP for 3 months \\
Babu $^{15}$ & Observational & 25 & $50.7 \pm 9.0$ & 64 & $42.7 \pm 8.7$ & $8.3 \pm 6.8$ & CPAP for $1-3$ months \\
Harsch $^{16}$ & Observational & 9 & $56.3 \pm 8.2$ & 77.8 & $36.7 \pm 5.3$ & $1(0.17,3)^{\text {a }}$ & CPAP (mean $91.4 \pm 35.5$ days) & $4.2 \pm 2.8 \pm 1.9$ \\
Brooks $^{17}$ & Observational & 10 & $50.8 \pm 9.6$ & 70 & $42.7 \pm 4.3$ & NA & CPAP for 4 months \\
\hline
\end{tabular}

Values are presented as mean \pm s.d. except where indicated.

Abbreviations: BMI, body mass index; CPAP, continuous positive airway pressure; NA, not available; RCT, randomised controlled trial.

${ }^{\text {a }}$ Data are summarised as median (interquartile range).

Table 2. Summary of $\mathrm{HbA1C}$, insulin sensitivity and BMI results before and after CPAP for studies included in the meta-analysis

\begin{tabular}{|c|c|c|c|c|c|c|c|c|c|}
\hline $\begin{array}{l}\text { First author } \\
\text { (year) }\end{array}$ & Before & After & $\begin{array}{c}\text { Before to after } \\
\text { difference }^{\mathrm{a}}\end{array}$ & Before & After & $\begin{array}{c}\text { Before to after } \\
\text { difference }^{\mathrm{a}}\end{array}$ & Before & After & $\begin{array}{c}\text { Before to after } \\
\text { difference }\end{array}$ \\
\hline Myhill $^{12}$ & $6.9 \pm 1.0$ & $6.9 \pm 1.1$ & $-0.07 \pm 0.11$ & NA & NA & NA & $33.6 \pm 5.5$ & $32.4 \pm 7.1$ & $-1.2 \pm 0.97$ \\
\hline Dawson $^{13}$ & $7.1 \pm 1.3$ & $7.2 \pm 1.3$ & $0.1 \pm 0.29$ & NA & NA & NA & $39.6 \pm 8.0$ & $39.9 \pm 8.1$ & $0.3 \pm 1.79$ \\
\hline West $^{14}$ & NA & NA & $-0.02 \pm 0.34$ & NA & NA & $1.7 \pm 3.15$ & $36.6 \pm 4.9$ & NA & $-0.2 \pm 0.22$ \\
\hline Brooks $^{17}$ & $8.9 \pm 1.5$ & $8.9 \pm 1.2$ & $0 \pm 0.44$ & $11.4 \pm 6.2$ & $15.1 \pm 4.6$ & $3.7 \pm 1.76$ & $42.7 \pm 4.3$ & $42.8 \pm 4.3$ & $0.1 \pm 1.36$ \\
\hline
\end{tabular}

Values are presented as mean \pm s.d. except where indicated.

Abbreviations: BMl, body mass index; CPAP, continuous positive airway pressure; HbA1c, glycosylated haemoglobin; NA, not available.

${ }^{\mathrm{a}}$ Data are summarised as mean \pm standard error.

and 11 underwent full-text review. Five were subsequently excluded and six $^{12-17}$ were included in the systematic review and meta-analysis.

\section{Study characteristics}

Characteristics of the six included studies are summarised in Table 1. We contacted the first author of one study ${ }^{12}$ to obtain mean and s.d. values, which allowed us to include that study in the present meta-analysis. Two of the studies were randomised controlled trials, and four were prospective observational (before and after) in design. The number of patients in the studies ranged from 9 to 44 (total $=128$ ), and the mean age ranged from 50.7 to 66.1 years. The majority $(\geqslant 60 \%)$ of patients in each study were male (range: $60-100 \%$ ). The mean baseline BMI ranged from $33.6 \mathrm{~kg} / \mathrm{m}^{2}$ to $42.7 \mathrm{~kg} / \mathrm{m}^{2}$. The duration of CPAP ranged from 1 to 4 months but was 3 months in four of the six studies. The length of CPAP use per night was reported in five of the six studies and ranged from 3.6 to 5.8 or $>5 \mathrm{~h}$ per night.

\section{Outcomes}

Systematic review. Table 2 summarises the key outcomes of the six included studies. For $\mathrm{HbA1c}$, decreases were observed in four studies, $^{12,14-16}$ and an increase was observed in one study. ${ }^{13}$ However, none of these changes were statistically significant. Three studies reported results for insulin sensitivity. ${ }^{14,15,17}$ In each case, improvements were observed; however, there was no statistically significant difference. There were no significant changes in BMI in the five studies reporting posttreatment values for BMI. ${ }^{12-14,16,17}$

Meta-analysis. All six studies were included in the meta-analysis of change in HbA1c level after CPAP (Figure 2a). No significant heterogeneity was detected $\left(Q=1.026, I^{2}=0 \%, P=0.960\right)$; hence, a fixed-effects model analysis was used. The combined standardised paired difference in mean change revealed no significant difference in $\mathrm{HbA} 1 \mathrm{c}$ before and after CPAP treatment $(P=0.421)$. We performed a subgroup analysis of $\mathrm{HbA} 1 \mathrm{c}$ level by comparing CPAP usage for $>5 \mathrm{~h} /$ night versus $\leq 5 \mathrm{~h} / \mathrm{hight}$. The results indicated no significant effect of CPAP on change in $\mathrm{HbA} 1 \mathrm{c}$ level with respect to hours of CPAP usage (Supplementary Figure 1).

Three studies ${ }^{14,16,17}$ were included in the meta-analysis of the change in insulin sensitivity after CPAP (Figure 2b). Significant heterogeneity was detected $\left(Q=2.017, P^{2}=86.41 \%, P=0.364\right)$; hence, a random-effects model of analysis was used. The combined standardised paired difference in mean change revealed that insulin sensitivity was significantly improved after CPAP treatment $(P=0.049)$

Five studies ${ }^{12-14,16,17}$ were included in the meta-analysis of the change in BMI after CPAP (Figure 2c). No heterogeneity was detected $\left(Q=1.284, I^{2}=0 \%, P=0.864\right)$; hence, a fixed-effects model analysis was used. The combined standardised paired difference in mean change revealed no significant difference in BMI before and after CPAP treatment $(P=0.302)$.

Figure 3 shows the results of the sensitivity analysis for the primary outcome (change in $\mathrm{HbA} 1 \mathrm{c}$ level) with one study removed in turns. The direction and magnitude of the pooled estimates did not show a large variation.

\section{Assessment of bias}

Figure 4 summarises the overall (a) and individual study (b) risk-ofbias assessments. In four studies, ${ }^{13,15-17}$ patients were not randomised to control/sham CPAP treatment. Rather, before and after comparisons were made for each patient. In the study reported by Myhill et al., ${ }^{12}$ the control group of patients did not receive sub- 


\begin{tabular}{lccccccc}
\hline First author (year) & $\begin{array}{c}\text { Std paired } \\
\text { difference }\end{array}$ & $\begin{array}{c}\text { Standard } \\
\text { error }\end{array}$ & Variance & $\begin{array}{c}\text { Lower } \\
\text { limit }\end{array}$ & $\begin{array}{c}\text { Upper } \\
\text { limit }\end{array}$ & $\boldsymbol{Z}$ value & $\boldsymbol{P}$ value \\
\hline Myhill (2012) & -0.095 & 0.151 & 0.023 & -0.391 & 0.202 & -0.626 & 0.531 \\
Dawson (2008) & 0.077 & 0.224 & 0.050 & -0.362 & 0.516 & 0.344 & 0.731 \\
West (2007) & -0.013 & 0.224 & 0.050 & -0.452 & 0.425 & -0.060 & 0.952 \\
Babu (2005) & -0.197 & 0.202 & 0.041 & -0.593 & 0.199 & -0.976 & 0.329 \\
Harsch (2004) & -0.152 & 0.335 & 0.112 & -0.810 & 0.505 & -0.455 & 0.649 \\
Brooks (1994) & 0.000 & 0.316 & 0.100 & -0.620 & 0.620 & 0.000 & 1.000 \\
Total (Fixed) & -0.071 & 0.089 & 0.008 & -0.245 & 0.103 & -0.804 & 0.421 \\
\hline Heterogeneity: Q-value $=1.026$, I-square $=0 \%, P$-value $=0.960$ & & &
\end{tabular}
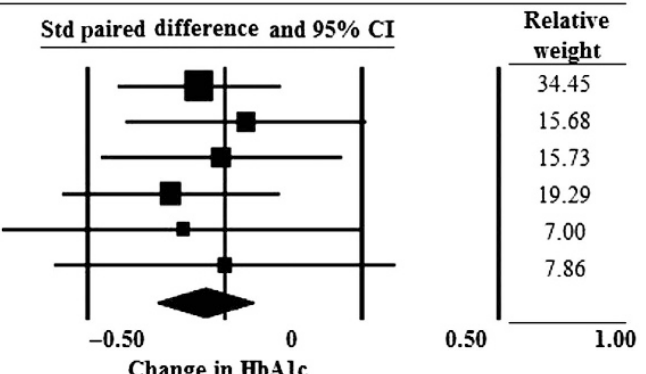

b

\begin{tabular}{lccccccc}
\hline First author (year) & $\begin{array}{c}\text { Std paired } \\
\text { difference }\end{array}$ & $\begin{array}{c}\text { Standard } \\
\text { error }\end{array}$ & Variance & $\begin{array}{c}\text { Lower } \\
\text { limit }\end{array}$ & $\begin{array}{c}\text { Upper } \\
\text { limit }\end{array}$ & $\boldsymbol{Z}$ value & $\boldsymbol{P}$ value \\
\hline West (2007) & 0.121 & 0.224 & 0.050 & -0.319 & 0.560 & 0.537 & 0.591 \\
Harsch $(2004)$ & 0.501 & 0.354 & 0.125 & -0.192 & 1.194 & 1.417 & 0.156 \\
Brooks (1994) & 0.664 & 0.349 & 0.122 & -0.021 & 1.348 & 1.900 & 0.057 \\
Total (Random) & 0.330 & 0.168 & 0.028 & 0.001 & 0.658 & 1.967 & 0.049 \\
\hline Heterogeneity: Q-value $=2.017$, I-square $=86.41 \%, P$-value $=0.364$ & & &
\end{tabular}

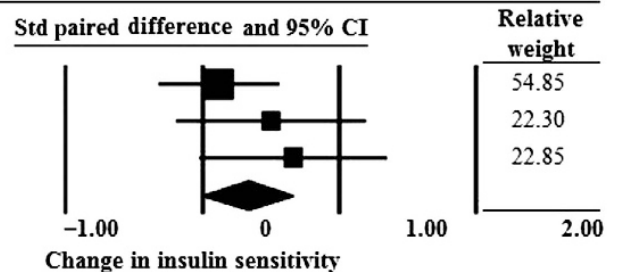

C

\begin{tabular}{lccccccc}
\hline $\begin{array}{l}\text { First author } \\
\text { (year) }\end{array}$ & $\begin{array}{c}\text { Std paired } \\
\text { difference }\end{array}$ & $\begin{array}{c}\text { Standard } \\
\text { error }\end{array}$ & Variance & $\begin{array}{c}\text { Lower } \\
\text { limit }\end{array}$ & $\begin{array}{c}\text { Upper } \\
\text { limit }\end{array}$ & $\boldsymbol{Z}$ value & $\boldsymbol{P}$ value \\
\hline Myhill (2012) & -0.186 & 0.152 & 0.023 & -0.484 & 0.112 & -1.223 & 0.221 \\
Dawson (2008) & 0.041 & 0.224 & 0.050 & -0.397 & 0.480 & 0.184 & 0.854 \\
West (2007) & -0.200 & 0.226 & 0.051 & -0.643 & 0.243 & -0.886 & 0.376 \\
Harsch (2004) & 0.056 & 0.334 & 0.111 & -0.598 & 0.710 & 0.168 & 0.867 \\
Brooks (1994) & 0.023 & 0.316 & 0.100 & -0.597 & 0.643 & 0.074 & 0.941 \\
Total (Fixed) & -0.102 & 0.099 & 0.010 & -0.296 & 0.092 & -1.032 & 0.302 \\
\hline Heterogeneity: Q-value $=1.284$ I-square $=0 \%, P$-value $=0.864$ & & &
\end{tabular}

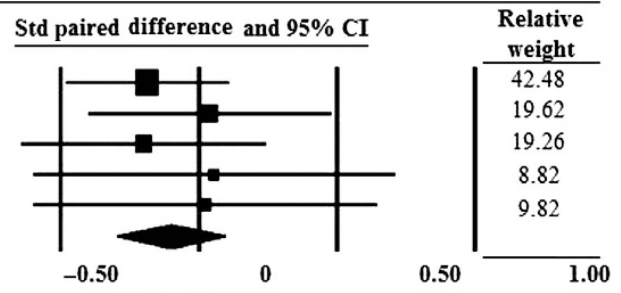

Change in BMII

Figure 2. Forest plots of major outcomes: change in (a) $\mathrm{HbA1c}$ level, (b) insulin sensitivity and (c) BMI after CPAP treatment. BMI, body mass index; $\mathrm{Cl}$, confidence interval; CPAP, continuous positive airway pressure; HbA1c, glycosylated haemoglobin; Std, standardised.

\begin{tabular}{lcccccccc} 
& \multicolumn{7}{c}{ Statistics with study removed } \\
\cline { 2 - 8 } $\begin{array}{l}\text { Removed } \\
\text { study }\end{array}$ & $\begin{array}{c}\text { Std paired } \\
\text { First author }\end{array}$ & $\begin{array}{c}\text { Standard } \\
\text { error }\end{array}$ & $\begin{array}{c}\text { Varianc } \\
\mathbf{e}\end{array}$ & $\begin{array}{c}\text { Lower } \\
\text { limit }\end{array}$ & $\begin{array}{c}\text { Upper } \\
\text { limit }\end{array}$ & $\boldsymbol{Z}$ value & $\boldsymbol{P}$ value \\
\hline Myhill (2012) & -0.059 & 0.110 & 0.012 & -0.274 & 0.156 & -0.539 & 0.590 \\
Dawson (2008) & -0.099 & 0.097 & 0.009 & -0.288 & 0.090 & -1.024 & 0.306 \\
West (2007) & -0.082 & 0.097 & 0.009 & -0.271 & 0.107 & -0.850 & 0.395 \\
Babu (2005) & -0.041 & 0.099 & 0.010 & -0.235 & 0.152 & -0.418 & 0.676 \\
Harsch (2004) & -0.065 & 0.092 & 0.008 & -0.245 & 0.115 & -0.709 & 0.478 \\
Brooks (1994) & -0.077 & 0.092 & 0.009 & -0.258 & 0.104 & -0.838 & 0.402 \\
Total & -0.071 & 0.089 & 0.008 & -0.245 & 0.103 & -0.804 & 0.421 \\
\hline & & & & & & & -1.00
\end{tabular}

Std paired difference $(95 \% \mathrm{CI})$ with studv removed

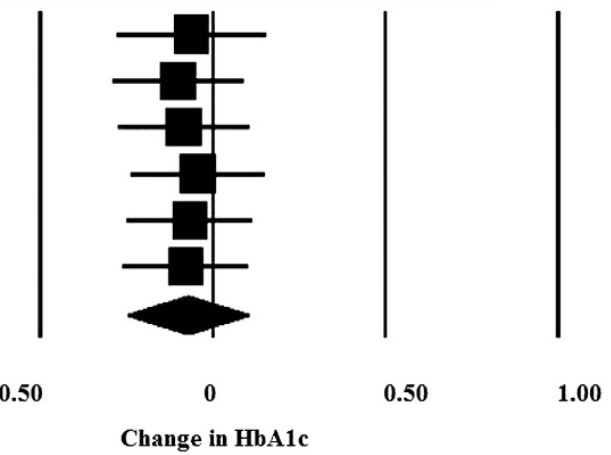

Figure 3. Sensitivity analysis for the influence of individual studies on the pooled estimate as determined by the leave-one-out method for change in $\mathrm{HbA} 1 \mathrm{c}$ level after CPAP treatment. $\mathrm{Cl}$, confidence interval; CPAP, continuous positive airway pressure; HbA1c, glycosylated haemoglobin; Std, standardised.

therapeutic CPAP for ethical reasons (i.e., restricting potentially effective therapy CPAP in a high-risk population). All studies were considered to have a low risk of attrition and reporting bias.

Supplementary Figure 2 shows the funnel plot for the assessment of publication bias for the primary outcome. There was marked evidence of symmetry, indicating a lack of publication bias.

\section{DISCUSSION}

Main finding

In this systematic review and meta-analysis, we obtained information from prospective studies examining the effects of CPAP on indicators of T2DM in patients with OSA and T2DM. A total of six studies, involving 128 patients, met the criteria for inclusion in our review and meta-analysis. Our findings indicate 
a

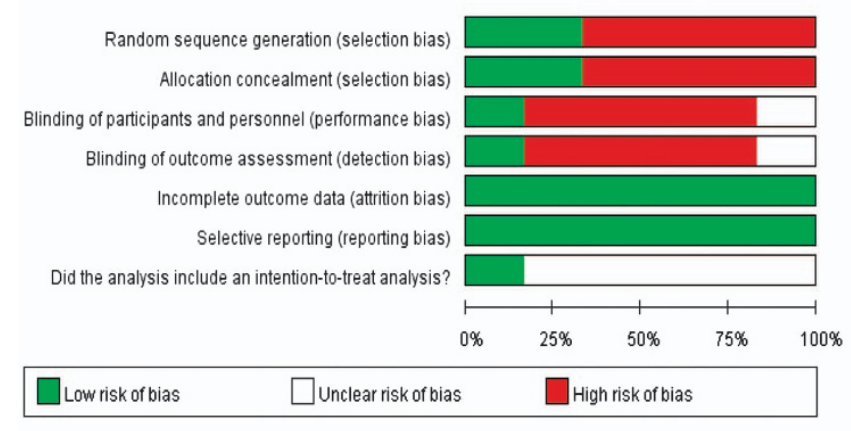

b

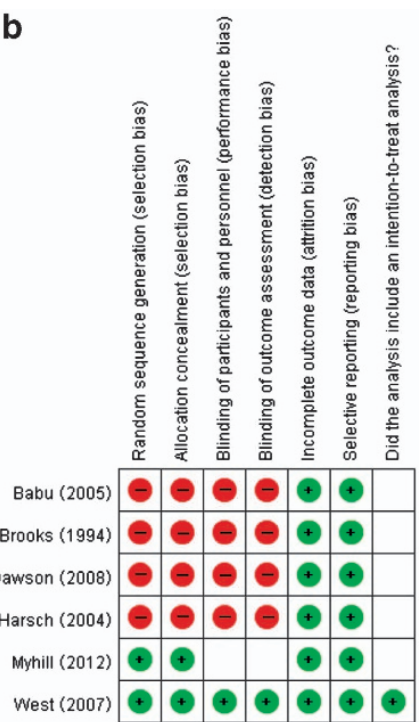

Figure 4. Summary of risk-of-bias assessment for studies included in the systematic review/meta-analysis.

that CPAP does not improve glycaemic control (indicated by $\mathrm{HbA1c}$ level) or BMI but may improve insulin sensitivity in patients with OSA and T2DM.

\section{Strengths and limitations of this study}

The present study has a number of limitations that warrant mention. First, each of the studies eligible for inclusion involved a small number of patients (no more than 44), and only one ${ }^{14}$ was a true randomised controlled trial (Myhill et al. ${ }^{12}$ pooled the treatment groups). The small number of patients clearly reduces the power of the results, and the fact that most studies were not randomised controlled trials means that the findings are not of the highest quality and may have been affected by varying levels of bias owing to the lack of randomisation and blinding. Of note, however, our assessment of bias did indicate that the risks of attrition and reporting bias were low. Further, our analyses revealed no evidence of publication bias. Second, although the studies were reasonably homogeneous in most areas, there was some between-study variability that may have affected outcomes and thus the results of our meta-analysis. Third, CPAP therapy was administered for a maximum of 4 months in the studies; hence, the findings from these studies, and indeed our meta-analysis, are only applicable to short-term CPAP. Prospective studies examining the effects of longer-term CPAP on indicators of T2DM would be welcome. Fourth, we must acknowledge that the meta-analyses of insulin sensitivity included only three studies and the metaanalyses of BMI included five studies; hence, these results must clearly be interpreted with some degree of caution. Fifth, there was no information on changes in the dietary and exercise habits of enrolled patients.

Interpretation of findings in relation to previously published work The rationale for the present meta-analysis is several-fold. First, although the review by Gallegos et al. ${ }^{9}$ also aimed to evaluate the effectiveness of CPAP, they did not focus on T2DM, including studies on prediabetes and metabolic syndrome. Prediabetes may involve a different pathophysiology of glucose metabolism. ${ }^{18}$ We believe a focus on T2DM is necessary to minimise heterogeneity of study subjects to avoid potential bias. Second, Gallegos et al. ${ }^{9}$ mixed several different outcome measures to evaluate glucose metabolism (i.e., $\mathrm{HbA1C}$, fasting glucose, insulin resistance (HOMA), insulin resistance (hyperinsulinaemic-euglycaemic clamp) and continuous glucose monitoring). Different parameters reflect different physiologic aspects. We believe it is necessary to evaluate the effect on each outcome measure individually. As we found in the present meta-analysis, CPAP had different effects on HbA1C and insulin. Third, Gallegos et al. ${ }^{9}$ conducted a systematic review, which did not include quantitative statistical analysis. Their conclusion that 'A few studies have shown that patients can experience even better results with long-term CPAP treatment ( $\geqslant 3$ months of daily use) for $>4 \mathrm{~h}$ a night.' came from only four studies and a lack of quantitative evidence. The present meta-analysis provides more quantitative information regarding the effect of CPAP.

Our finding that CPAP did not significantly improve (i.e., decrease) HbA1c level in patients with OSA and T2DM is consistent with the finding of Iftikhar et $a l^{8}{ }^{8}$ in a previous systematic review and meta-analysis (mean difference: $0.08 ; 95 \%$ confidence interval $(\mathrm{Cl}):-0.26,0.42 ; P=0.65)$, which included four of the same studies ${ }^{13-16}$ included in our meta-analysis and one retrospective study ${ }^{19}$ that was not eligible for inclusion in our analysis. Similarly, our findings regarding $\mathrm{HbA} 1 \mathrm{c}$ are consistent with those reported by Hecht et al., ${ }^{20}$ who carried out a systematic review and meta-analysis examining the effects of CPAP on insulin resistance and glucose metabolism in patients with OSA (metaanalysis of $\mathrm{HbA} 1 \mathrm{c}$ mean difference: $0.04,95 \% \mathrm{Cl}$ : $-1.06,1.14$; $P=0.94)$. Taken together, we believe that the available evidence suggests that CPAP is unlikely to provide clinically meaningful improvement in glycaemic control for individuals with OSA and T2DM. However, there is interesting evidence suggesting that longer CPAP usage per night in this patient population might improve HbA1c level. ${ }^{21}$ As stated, Gallegos et al. ${ }^{9}$ reported improvement in $\mathrm{HbA1c}$ level only after long-term CPAP use ( $\geqslant 3$ months). An effect of CPAP on HbA1c could potentially occur in relation to other factors: for example, the duration of diabetes.

Interestingly, and in contrast to $\mathrm{HbA1c}$, the results of our metaanalysis suggest that CPAP may improve insulin sensitivity in patients with OSA and T2DM. To our knowledge, this is the first meta-analysis of this variable in patients with T2DM. However, Hecht et al. ${ }^{20}$ examined both insulin level and the HOMA index as part of their meta-analysis of variables in patients with OSA and found that CPAP did not improve either (insulin mean difference: $-2.95 ; 95 \% \mathrm{Cl}:-20.39,14.50 ; P=0.74 ;$ HOMA mean difference: $-0.77 ; 95 \% \mathrm{Cl}:-4.12,2.57 ; P=0.65)$. Consistent with our findings, Lindberg et al. ${ }^{22}$ carried out a study on patients with OSA and found that CPAP led to improvement in insulin sensitivity (as indicated by serum insulin and HOMA measures) but not in $\mathrm{HbA1C}$ 
levels. Similarly, Weinstock et al. ${ }^{23}$ found that insulin sensitivity was improved in patients with severe OSA and impaired glucose tolerance after 8 weeks of CPAP. Taken together, we believe that there is some evidence that CPAP may improve insulin sensitivity in patients with OSA and T2DM. It is important to mention that, if CPAP does improve insulin sensitivity, any HbA1c improvement would occur in the context of functional beta cells. If the diabetes duration is long and the patient is lacking functional beta cells, CPAP would be unlikely to affect $\mathrm{HbA1c}$ level.

Meta-analysis of studies reporting changes in BMI with CPAP in patients with OSA and T2DM revealed no significant effects of therapy. This finding is consistent with those from several studies of CPAP in patients with $\mathrm{OSA}^{24,25}$ and suggests that CPAP is unlikely to decrease BMI in patients with OSA and T2DM. As to whether changes in insulin sensitivity might be related to changes in BMI, the three studies reporting results for both of these variables suggest no correlation. ${ }^{14,16,17}$

The results of the present meta-analysis supporting an improvement in insulin sensitivity (i.e., increased sensitivity), but no change in $\mathrm{HbA} 1 \mathrm{c}$ level, in response to CPAP in patients with OSA and T2DM are consistent with findings in subjects without T2DM. Meta-analyses by Iftikhar et al. ${ }^{26}$ and Yang et al. ${ }^{27}$ both found improvement in insulin resistance (i.e., decreased resistance), according to HOMA measurements, in response to CPAP in nondiabetic subjects. No significant effect on $\mathrm{HbA} 1 \mathrm{c}$ level was found in nondiabetic subjects in another meta-analysis by Iftikhar et al. ${ }^{8}$

OSA severity is directly associated with the level of insulin resistance, and intermittent hypoxia, sleep fragmentation and nocturnal arousal comprise potential mechanisms that may result in impaired glucose tolerance. ${ }^{28}$ For example, intermittent hypoxia is reported to impair glucose tolerance, possibly via increased oxidative stress and lipid peroxidation. Recurrent hypoxic episodes activate the sympathetic nervous system and increase the release of catabolic hormones, which can foster the development of T2DM. ${ }^{29}$ Sleep fragmentation is another mechanism through which OSA might affect glucose metabolism. ${ }^{30}$ In healthy subjects, sleep restriction is associated with insulin resistance, increased appetite and carbohydrate craving, and, even in the absence of breathing disorders, sleep fragmentation and sleep deprivation can affect glucose tolerance. ${ }^{31}$ Nocturnal awakening and arousal are associated with altered levels of leptin, leptin resistance, pulsatile cortisol release and autonomic activation. Repeated arousal and subsequent cortisol release can lead to dysregulation of the hypothalamic-pituitary-adrenal axis, resulting in glucose impairment. ${ }^{32}$ This may have a role in modulating insulin levels and foster the development of T2DM. CPAP significantly decreases hypoxemic stress, sympathetic drive and sleep fragmentation by delivering constant pressure throughout inspiration and expiration to maintain upper-airway patency during sleep. ${ }^{33,34}$

Implications for future research, policy and practice

Given the lack of information from large-scale studies, evidence from additional randomised controlled trials is needed to determine conclusively whether CPAP is an effective treatment for T2DM in this context. Additional prospective trials involving larger patient populations (and indeed more lengthy treatment) are a more realistic goal.

\section{Conclusions}

The available evidence suggests that CPAP does not decrease $\mathrm{HbA1C}$ level or BMI in patients with OSA and T2DM but may improve insulin sensitivity in these patients.

\section{CONTRIBUTIONS}

YF contributed to the concept and design of the study. YF carried out the statistical analyses with input from YF and ZZ while Z-zD undertook the clinical interpretation of the data. YF and ZZ contributed to the manuscript editing and manuscript review.

\section{COMPETING INTERESTS}

The authors declare no conflict of interest.

\section{FUNDING}

No sponsors were involved in this study.

\section{REFERENCES}

1 Young T, Peppard PE, Gottlieb DJ. Epidemiology of obstructive sleep apnea: a population health perspective. Am J Respir Crit Care Med 2002; 165: 1217-1239.

2 Young T, Peppard PE, Taheri S. Excess weight and sleep-disordered breathing J Appl Physiol (1985) 2005; 99: 1592-1599.

3 Lattimore JD, Celermajer DS, Wilcox I. Obstructive sleep apnea and cardiovascular disease. J Am Coll Cardiol 2003; 41: 1429-1437.

4 Schlatzer C, Schwarz El, Kohler M. The effect of continuous positive airway pressure on metabolic variables in patients with obstructive sleep apnoea. Chron Respir Dis 2014; 11: 41-52.

5 Pamidi S, Tasali E. Obstructive sleep apnea and type 2 diabetes: is there a link? Front Neurol 2012; 3: 126

6 Chakhtoura M, Azar ST. Continuous positive airway pressure and type 2 diabetes mellitus. Diabetes Metab Syndr 2012; 6: 176-179.

7 Surani S, Subramanian S. Effect of continuous positive airway pressure therapy on glucose control. World J Diabetes 2012; 3: 65-70.

8 Iftikhar $\mathrm{IH}$, Blankfield RP. Effect of continuous positive airway pressure on hemoglobin $\mathrm{A}(1 \mathrm{c})$ in patients with obstructive sleep apnea: a systematic review and meta-analysis. Lung 2012; 190: 605-611.

9 Gallegos L, Dharia T, Gadegbeku AB. Effect of continuous positive airway pressure on type 2 diabetes mellitus and glucose metabolism. Hosp Pract (1995) 2014; 42: 31-37.

10 Higgins JPT, Green S. Cochrane Collaboration. Cochrane Handbook for Systematic Reviews of Interventions. Wiley-Blackwell: Hoboken, NJ, USA, 2008.

11 Deeks JJ, Higgins JPT, Altman DG (eds). Chapter 9: Analysing data and undertaking meta-analyses. In: Higgins JPT, Green S (eds) Cochrane Handbook for Systematic Reviews of Interventions, Version 5.1.0 (updated March 2011) The Cochrane Collaboration, 2011, Available from www.cochrane-handbook.org.

12 Myhill PC, Davis WA, Peters KE, Chubb SA, Hillman D, Davis TM. Effect of continuous positive airway pressure therapy on cardiovascular risk factors in patients with type 2 diabetes and obstructive sleep apnea. J Clin Endocrinol Metab 2012; 97: 4212-4218.

13 Dawson A, Abel SL, Loving RT, Dailey G, Shadan FF, Cronin JW et al. CPAP therapy of obstructive sleep apnea in type 2 diabetics improves glycemic control during sleep. J Clin Sleep Med 2008; 4: 538-542.

14 West SD, Nicoll DJ, Wallace TM, Matthews DR, Stradling JR. Effect of CPAP on insulin resistance and $\mathrm{HbA} 1 \mathrm{c}$ in men with obstructive sleep apnoea and type 2 diabetes. Thorax 2007; 62: 969-974.

15 Babu AR, Herdegen J, Fogelfeld L, Shott S, Mazzone T. Type 2 diabetes, glycemic control, and continuous positive airway pressure in obstructive sleep apnea. Arch Intern Med 2005; 165: 447-452.

16 Harsch IA, Schahin SP, Brückner K, Radespiel-Tröger M, Fuchs FS, Hahn EG et al. The effect of continuous positive airway pressure treatment on insulin sensitivity in patients with obstructive sleep apnoea syndrome and type 2 diabetes. Respiration 2004; 71: 252-259.

17 Brooks B, Cistulli PA, Borkman M, Ross G, McGhee S, Grunstein RR, Sullivan CE et al. Obstructive sleep apnea in obese noninsulin-dependent diabetic patients: effect of continuous positive airway pressure treatment on insulin responsiveness. J Clin Endocrinol Metab 1994; 79: 1681-1685

18 Abdul-Ghani MA, Tripathy D, DeFronzo RA. Contributions of beta-cell dysfunction and insulin resistance to the pathogenesis of impaired glucose tolerance and impaired fasting glucose. Diabetes Care 2006; 29: 1130-1139.

19 Hassaballa HA, Tulaimat A, Herdegen JJ, Mokhlesi B. The effect of continuous positive airway pressure on glucose control in diabetic patients with severe obstructive sleep apnea. Sleep Breath 2005; 9: 176-180.

20 Hecht L, Mohler R, Meyer G. Effects of CPAP-respiration on markers of glucose metabolism in patients with obstructive sleep apnoea syndrome: a systematic review and meta-analysis. Ger Med Sci 2011; 9: Doc20. 
21 Grimaldi D, Beccuti G, Touma C, Van Cauter E, Mokhlesi B. Association of obstructive sleep apnea in rapid eye movement sleep with reduced glycemic control in type 2 diabetes: therapeutic implications. Diabetes Care 2014; 37: 355-363.

22 Lindberg E, Berne C, Elmasry A, Hedner J, Janson C. CPAP treatment of a population-based sample--what are the benefits and the treatment compliance? Sleep Med 2006; 7: 553-560.

23 Weinstock TG, Wang X, Rueschman M, Ismail-Beigi F, Aylor J, Babineau DC et al. A controlled trial of CPAP therapy on metabolic control in individuals with impaired glucose tolerance and sleep apnea. Sleep 2012; 35: 617-625B.

24 Harsch IA, Konturek PC, Koebnick C, Kuehnlein PP, Fuchs FS, Pour Schahin S et al. Leptin and ghrelin levels in patients with obstructive sleep apnoea: effect of CPAP treatment. Eur Respir J 2003; 22: 251-257.

25 Coughlin SR, Mawdsley L, Mugarza JA, Wilding JP, Calverley PM. Cardiovascular and metabolic effects of CPAP in obese males with OSA. Eur Respir J 2007; 29: 720-727.

26 Iftikhar IH, Khan MF, Das A, Magalang UJ. Meta-analysis: continuous positive airway pressure improves insulin resistance in patients with sleep apnea without diabetes. Ann Am Thorac Soc 2013; 10: 115-120.

27 Yang D, Liu Z, Yang H, Luo Q. Effects of continuous positive airway pressure on glycemic control and insulin resistance in patients with obstructive sleep apnea: a meta-analysis. Sleep Breath 2013; 17: 33-38.

28 Kono M, Tatsumi K, Saibara T, Nakamura A, Tanabe N, Takiguchi $\mathrm{Y}$ et al. Obstructive sleep apnea syndrome is associated with some components of metabolic syndrome. Chest 2007; 131: 1387-1392.
29 Pallayova M, Lazurova I, Donic V. Hypoxic damage to pancreatic beta cells--the hidden link between sleep apnea and diabetes. Med Hypotheses 2011; 77: 930-934.

30 Knutson KL, Spiegel K, Penev P, Van Cauter E. The metabolic consequences of sleep deprivation. Sleep Med Rev 2007; 11: 163-178.

31 Spiegel K, Tasali E, Penev P, Van Cauter E. Brief communication: sleep curtailment in healthy young men is associated with decreased leptin levels, elevated ghrelin levels, and increased hunger and appetite. Ann Intern Med 2004; 141: 846-850.

32 Buckley TM, Schatzberg AF. On the interactions of the hypothalamic-pituitaryadrenal (HPA) axis and sleep: normal HPA axis activity and circadian rhythm, exemplary sleep disorders. J Clin Endocrinol Metab 2005; 90: 3106-3114.

33 Chaktoura M, Azar ST. Continuous positive airway pressure and type 2 diabetes mellitus. Diabetes Metab Syndr 2012; 6: 176-179.

34 Coy TV, Dimsdale JE, Ancoli-Israel S, Clausen J. Sleep apnoea and sympathetic nervous system activity: a review. J Sleep Res 1996; 5: 42-50.

(c) (1) $\ominus$ This work is licensed under a Creative Commons AttributionNonCommercial-NoDerivatives 4.0 International License. The images or other third party material in this article are included in the article's Creative Commons license, unless indicated otherwise in the credit line; if the material is not included under the Creative Commons license, users will need to obtain permission from the license holder to reproduce the material. To view a copy of this license, visit http:// creativecommons.org/licenses/by-nc-nd/4.0/

Supplemental Information accompanies the paper on the npj Primary Care Respiratory Medicine website (http://www.nature.com/npjpcrm) 